\title{
Identidad cultural latinoamericana: la mirada heteróclita y la reivindicación del indígena
}

\author{
Xiomara Leticia Moreno
}

Recibido: 10.05.2020 — Aceptado: 1.06.2020

\section{Title / Titre / Titolo}

Latin American Cultural Identity: The Heteroclite gaze and the Claim of the Indigenous

Identité culturelle latin américaine : le regard hétéroclite et les réclamations autochtones

L'identità culturale latinoamericana: lo sguardo eteroclito e le rivendicazioni degli indigeni

\section{Resumen / Abstract / Résumé / Riassunto}

Se presentan dos perspectivas que buscan definir la concepción de una identidad cultural latinoamericana. La sustentada en el colonialismo heteróclito y, la más actual, de las reivindicaciones indígenas. Ambas han sido preocupaciones recorridas desde el siglo XIX como posibles salidas para un reconocimiento de un ser cultural identificable por cada uno de los fragmentos que conforman los Estados nacionales en América Latina. La reflexión se sustenta en autores como Mariano Picón Salas, José Carlos Mariátegui, Octavio Paz, Roberto Fernández Retamar, Augusto Roa Bastos, Arturo Uslar Pietri, John Beverley, y Ronny Velásquez, entre otros estudiosos de la cultura.

Two perspectives are presented that seek to define the notion of a Latin American cultural identity. One is sustained by heteroclite colonialism, the other, a more recent one, sustained by the indigenous communities' claims. Both have been present since the nineteenth century as possible standpoints for the acknowledgment of each of the fragments constituting Latinamerican national States. The considerations proposed are supported by the work of authors such as Mariano Picón Salas, José Carlos Mariátegui, Octavio Paz, Roberto Fernández Retamar, Augusto Roa Bastos, Arturo Uslar Pietri, John Beverley and Ronny Velásquez, among other cultural critics.
Deux perspectives sont présentées qui cherchent à définir la conception d'une identité culturelle latino-américaine. Colonialisme hétérogène soutenue et, plus actuellement, communautés autochtones. Tous deux sont enregistrés depuis le XIXe siècle comme des points de vue possibles pour une reconnaissance de leur identification culturelle pour chacun des fragments qui composent les États nationaux d'Amérique latine. La réflexion a le soutien d'auteurs tels que Mariano Picón Salas, José Carlos Mariátegui, Octavio Paz, Roberto Fernández Retamar, Augusto Roa Bastos, Arturo Uslar Pietri, John Beverley, et Ronny Velásquez, entre autres universitaires culturels.

Nell'articolo si presentano due prospettive che intendono definire la concezione di un'identità culturale latinoamericana: una basata nel colonialismo eteroclito, l'altra, più attuale, basata sulle rivendicazioni degli indigeni. Entrambe sono presenti dal XIX secolo come punti di vista possibili per il riconoscimento di una entità culturale per ciascuno dei frammenti che compongono gli Stati nazionali dell'America Latina. La riflessione ha il supporto di riferimenti come Mariano Picón Salas, José Carlos Mariátegui, Octavio Paz, Roberto Fernández Retamar, Augusto Roa Bastos, Arturo Uslar Pietri, John Beverley e Ronny Velásquez, tra altri studiosi della cultura.

\section{Palabras clave I Keywords I Mots-clé / Parole chiave}

Cultura, identidad cultural, reivindicación indígena.

Culture, cultural identity, indigenous rights.

Culture, identité culturelle, droits autochtones.

Cultura, identità culturale, diritti degli indigeni. 


\section{La mirada heteróclita}

Desde el siglo XIX, en América Latina se ha hecho común hablar de crisis social como sinónimo de crisis cultural debido a que los términos de cultura y sociedad se amalgamaron en la lucha entre la tendencia oficialista que quería mantener una cultura tradicional en estas tierras, heredada de su etapa como colonia española, y otra, la enfrentada a ésta. En ese sentido, la concepción de cultura propuesta por la avanzada intelectual en el siglo XX, y específicamente en la primera mitad del siglo, era la siguiente: la cultura «extrae y elabora su propia existencia histórica en cada pueblo» (Picón Salas, 12). Es decir, la cultura era concebida como el motor que impulsaría a los pueblos a ser dueños de sus propios procesos históricos y, en consecuencia, de su devenir, sin que éste tuviera nada que ver con la búsqueda de un progreso económico, material ni tecnológico, sino como una tarea a partir de la cual se reconocía que la cultura de Latinoamérica había sido construida de «retazos» venidos de todas partes y que, de esa manera, se había extraviado la búsqueda y la comprensión de los propios fines de la cultura, por lo que ya era tiempo de enrumbarse en la asimilación de lo que se había construido.

Este camino se hizo especialmente presente con el Modernismo de principios del siglo XX, con el cual no se ignoró la realidad presente, como comúnmente se le ha acusado, sino que se presentó como propuesta para el inicio de una historia de la cultura hispanoamericana propia. La intención de esta búsqueda se sustentaba en que «Por los caminos universales, ... que tanto se nos reprochan, nos vamos acercando cada vez más a nosotros mismos» (Mariátegui, 288). Así, los años que van de la década de los veinte a la de los cuarenta del siglo XX fueron los más fuertes constructores del hibridismo cultural que trascendió todo el siglo, y que los latinoamericanos aceptaron «libres de los prejuicios xenófobos de las viejas culturas europeas» (Picón Salas, 188).

A pesar de este colonialismo heteróclito, que conllevaba la triple acción del liberalismo, del positivismo y del modernismo, se movió la conciencia intelectual sobre lo cultural en América Latina, y se buscó definir las circunstancias y la historia de la misma. Se emprende la búsqueda de la historia propia desde el pensamiento, desde la cultura y desde el reencuentro de la tradición con la necesidad ética preocupada por el destino de este mundo, al cual se le aceptó con la denominación del «Nuevo Mundo». ${ }^{1}$ De esta manera, y para liquidar ciertas formas aldeanas, se buscó una identidad de lo que sería una conciencia de la propia realidad en su relación con la historia occidental.

La Latinoamérica de mediados del XX se buscaría en «Babilonias y Alejandrías en la medida de sus recursos y fronteras» $(\mathrm{Paz}, 18)$, para huir

...de los pueblos miserables, de los tiranos y dictadores que se turnan el poder... volcanes en erupción, guerrilleros de machete, marinos yanquis en los pueblecitos tropicales a poner orden entre los nativos. Y tierras hipotecadas a los extranjeros... (Picón Salas, 35).

Lo que pudo ser una reflexión sobre un ser o una manera de ser del latinoamericano generó un exilio voluntario hacia la irresponsabilidad moral carente de sanciones. Una evasión que le permitió superar el aislamiento de la colonia y de las batallas independentistas, ya abandonadas por sí mismas y por sus políticos. En esa huida, se planteó actualizar lo autóctono, con la ayuda de Francia e Inglaterra, naciones que tenían un gran interés en los mercados del otrora imperio español. Esto generó una cultura de universalidad en Latinoamérica que no diferenciaba entre nacionalidades ni entre especificidades culturales, sino que hacía amalgama de una pluralidad cultural venida de las ideas que procedían de los objetos culturales que se le ofrecían como un botín de belleza y cultura venida de otra parte; pero en un plano doméstico, cotidiano y del día a día, se mantenía una cultura invisible que todavía estaba bajo el peso de la cultura medieval de la colonia española.

\footnotetext{
${ }^{1}$ Una expresión creada por los europeos, proyectada en América y asimilada por los modernistas.
} 
Con la rearticulación de la colonia, ahora heteróclita, el lenguaje se vuelve un asunto de discusión como cosa en sí, como objeto, como instrumento o como un objeto más de la realidad histórica y social y, como tal, se entiende como parte de la mentalidad y sensibilidad coloniales, lo que entorpecía la captación de la realidad del presente y evadía la constatación de una «realidad deformada por las estructuras de dominación y explotación» (Roa, 116). Esta crisis de referencias habla, en específico, de dos planos de captación de la realidad: la experiencia del mundo vivido dentro del mundo conocido, es decir, la realidad tal cual aparenta ser, y la realidad tal cual es, y el problema en ello está en que se dificulta una clara definición y limitación entre estas realidades, la que es y la que aparenta ser.

Según el cubano Roberto Fernández Retamar, en los años sesenta del siglo XX se iniciaron los pequeños nacionalismos, nacidos del reconocimiento y la imposibilidad de Latinoamérica en «realizarse como proyecto burgués» (51). Nacionalismos nacidos con la inconsciencia de quienes no tienen pasado, porque «sin pasado se podía ser de cualquier parte, lo cual también significaba no serlo de ninguna» (36).

Mientras se asumían diversos modelos en un plano intelectual, literario y artístico, los cuales eran modificados en una actividad dialéctica y sincrética de alto nivel, en Latinoamérica se estaba produciendo una nueva crisis colonial de corte referencial. Es justamente en esa segunda mitad del siglo XX que se tuvo una postura mucho más crítica, en el sentido de mantener una reflexión ante las doctrinas hegemónicas, siendo una de las grandes revisiones el asunto de la identidad cultural latinoamericana. Con ello, el pensamiento latinoamericanista no siguió buscando arrancarse una parte fundamental de su ser histórico social, como lo hizo en el siglo XIX. Hasta la propia condición de ausencia de pasado es vista desde otra perspectiva, donde se revelan las carencias que hacen conflictiva la identidad. Carencias referidas a tradición, a historia y a territorio, y relacionadas con la cultura enmudecida del indígena. Carencias que no hablan de un centro hegemónico de convergencia universal, sino de separación, de disgre- gación, de concentración de un pasado que no es plenamente asimilado y que por lo tanto tiende a repetirse en el presente. De esta manera,

Hispanoamérica seguía negándose a considerar como parte de su historia un pasado que no había hecho... La historia que ahora los hispanoamericanos de mediados del siglo XX [les] toca negar dialécticamente, esto es, asimilar (Zea, 1976, p. 59).

Durante el siglo XX, la necesidad de un proceso de recuperación del pasado reafirmó una identidad emergente subsidiaria, ya que no se consideraron realmente los nódulos conflictivos de la hibridez, que ha sido fomentada por la capacidad de asimilación de nuestro pasado-presente colonial, y tampoco se hizo la revisión de la conciencia indigenista y el aporte simbólico y estético de las culturas prehispánicas. Se inicia la asimilación referida a una historia cultural del desarraigo y en perpetua relación con otras culturas, con un tejido de relaciones que, además, tienen la dificultad de ser híbridas y no lineales, y que ha demostrado su «genuina e irrenunciable capacidad de asimilación aluvional» (Uslar Pietri, 23). Porque era más fácil reconocer la identidad latinoamericana que definirla. Con lo cual se buscó determinar qué productos de la cultura latinoamericana no dependían del sincretismo con otras culturas y, no por ello, negar la influencia o la enorme herencia de la cultura occidental en la configuración de Latinoamérica.

Por otro lado, el desequilibrio y la angustia contemporánea de lo que corresponde a una crisis del capitalismo también generaba su reflejo en la cultura latinoamericana, lo que permitía decir que la crisis de la cultura capitalista en el hemisferio sur estaba presente en la forma de centralización económica, política y cultural de los Estados nacionales y que se han heredado hasta la actualidad. Es decir, como causa y consecuencia de la historia de regímenes autoritarios que se han entronizado y que han dado paso, junto a la globalización, a una cultura política de tradición socialdemócrata que se caracteriza por ajustar reivindicaciones obreras y populares a los intereses del capital, ofreciéndose como una manera de mediación eficaz entre las luchas 
de clases. Lo cual no es una propuesta como tal, sino que es una de las ya tradicionales formas de modernidad y por las cuales Latinoamérica se ha visto seducida (Beverley).

\section{Una mirada de reivindicación indígena}

Es en lo que va del siglo XXI que se deja ver en Latinoamérica uno de los principios reivindicativos en cuanto identidad cultural: el de dejar de asumir las culturas indígenas como ruinas del pasado o concebidas como culturas que ya no existen, o como si dentro de un proceso evolutivo hubiesen desaparecido sin dejar rastros o consecuencias en la actualidad. Esta reivindicación se ha planteado acabar, no sólo con la invisibilización en presente de todos los pueblos indígenas existentes en el territorio latinoamericano, sino también detener la programada desaparición cultural de los indígenas -validada cuando fueron entregados a los diversos procesos religiosos para su civilización, ya que todos estos pueblos indígenas fueron considerados paganos, salvajes y antropófagos-. Favorablemente, no fue efectivo el proceso de exterminio y en la actualidad hay pueblos indígenas que conservan, en sus saberes, sus propias lógicas y maneras de pensar, y a partir de interpretaciones etnográficas se puede llegar a leer en tallas en piedra o en tejidos, en cerámica, en petroglifos o en rituales, todo un pasado lleno de metáforas que los indígenas actuales guardan de manera celosa en sus cantos chamánicos, en su oralidad o en sus pensamientos más etnográficos o etno-estéticos.

Se han establecido relaciones entre los distintos fenómenos socioculturales, particularizados, identificados y desarrollados por los pueblos indígenas con fines de análisis y de valorar si todos estos pueblos han sido sometidos o si han sido irrespetados en su propia etnohistoria, si han sido considerados o no en sus propios sistemas educativos, para profundizar la comprensión de los fenómenos sociohistóricos de los pueblos indígenas del presente. Especialmente desde el punto de vista del estudio de la cultura intangible, se valoran sus expresiones no materiales, como la religión, los rituales o los aspectos sociales y políticos que han estado presentes en sus expresiones prehispánicas y siguen estando también en las sociedades indígenas contemporáneas.

Ante la evidencia de que en la actualidad hay, en toda América, por lo menos cinco mil pueblos indígenas con lenguas diferentes y que han tenido diversos grados de desenvolvimiento, según el área en la cual se han asentado para hacer su vida y de su proceso migratorio en el continente ${ }^{2}$. También es posible analizar comparativa y descriptivamente las expresiones tangibles e intangibles de una o más culturas indígenas para establecer relaciones entre fenómenos interculturales o de intercambio en territorios americanos que hoy nos parecen distantes, pero que, durante los procesos de las grandes migraciones indígenas, tuvieron comunicación. Por ejemplo, los pueblos indígenas que vivieron y viven en las cuencas del río Orinoco, en el Estado Amazonas de Venezuela, se relacionaban a través del trueque de su oro, el cual viajó a lo largo del continente y fue procesado como arte en culturas prehispánicas de Colombia, Guatemala, Honduras y México. Por lo que la apertura a la cultura de los pueblos indígenas compromete el reconocer sus relaciones con otras culturas indígenas.

Asumiendo que la cultura latinoamericana deviene como producto de diversos sistemas de colonización que conviven en este continente, podemos decir que los cinco idiomas fundamentales que se hablan en la América actual son los idiomas oficiales de quienes colonizaron desde el siglo XV. Tal como el inglés, el castellano, el portugués, el francés y el holandés; los cuales, en la actualidad, son aceptados como lenguas oficiales de nuestros países sin valorar que las raíces lingüísticas de esas lenguas oficiales también han sido el timote, cuica, yanomami, el wayuu, el yukpa, el inka, el kuna, maya, el nahua o azteca, o cualquier otro idioma de los cien millones de personas originarias de este continente que se fueron adaptando durante más de sesenta mil años antes de la llegada de la conquista. Aunque estas

2 Cfr. Velásquez, 2012. 
lenguas fueron idiomas llevados al punto de la extinción definitiva por más de quinientos años de coloniaje, todavía quedan, y todavía siguen germinando, surgiendo y resurgiendo.

Se pueden citar muchísimos ejemplos del desprecio y del exterminio del indio y estos datos son hoy parte de la historia reciente, como ocurrió con la matanza de los indios Barí en la Sierra de Perijá, Estado Zulia en 1960, o la matanza perpetrada por unos hacendados contra los indígenas Cuiva y Pumé en el Río Capanaparo, Estado Apure en 1970, en Venezuela. Lo que también denota que el problema con la cultura indígena no es sólo el conflicto étnico, el problema es económico, religioso, y el temor que causa el hecho de que el indígena tenga la posibilidad de recuperar lo perdido. Esto no sólo incluye su religiosidad, sus chamanes, sus idiomas, su cultura en general, sino también, el reclamo de sus territorios y de sus riquezas arrebatadas.

La voz de los indígenas se ha hecho presente en Ginebra ante las Naciones Unidas, el 13 de septiembre del año 2007, cuando se aprobó de manera definitiva, después de veinte años de discusión y de sesenta y una sesiones y asambleas, la Declaración de las Naciones Unidas sobre los Derechos de los Pueblos Indígenas del Mundo, con uno de los artículos más controversiales: «Los pueblos indígenas tienen el derecho a tierras, territorios y recursos que han sido suyos tradicionalmente, y también a recursos y tierras que hayan comprado, usado o adquirido» ${ }^{3}$ (OEA, 8). Por este artículo, entre tantos otros de los cuarenta que componen esta declaración, surgen las Leyes sobre Territorialidad de los Pueblos Indígenas, con las cuales reclaman sus propios derechos a los Estados que los excluyeron por tanto tiempo y que ahora desean entregar a las transnacionales, el petróleo, el hierro y todos los recursos de sus territorios.

\footnotetext{
${ }^{3}$ Entre los diversos postulados de la Declaración de las Naciones Unidas sobre los Derechos de los Pueblos Indigenas, destaca lo siguiente:

Somos conscientes de la urgente necesidad de respetar y promover los derechos intrínsecos de los pueblos indígenas, que derivan de sus estructuras políticas, económicas y sociales y de sus culturas, de sus tradiciones espirituales, de su historia y de su concepción de la vida, especialmente los derechos a sus tierras, territorios y recursos (OEA, 2007, p. 2).
}

En la Movilización Continental de los Pueblos Indígenas de Abya Yala ${ }^{4}$ se postula:

Es nuestro reto construir una Patria Grande, con una característica plurinacional, uniendo los actuales Estados en una Comunidad como fue Abya Yala, con un nuevo contrato social que involucre los derechos de todos y para todos. Por eso planteamos una refundación y no la continuidad de los Estadosnación sumidos en la corrupción y la deuda. Es vital iniciar este proceso en todos los Estados de Latinoamérica sin excluir a nadie. Jallalla Pueblos Indígenas! ¡Kausachun Pueblos Indígenas! (Velásquez, 2012: s/n).

El hecho de tomar en cuenta este largo reclamo, ha generado verdaderos actos de rectificación simbólica, por ejemplo, que en Venezuela se instituya, en el año 2004, el «Día de la Resistencia Indígena», y que en el 2003 se haga la publicación de la Constitución de 1999 en el idiomas Wayuú-naiki, que lo hablan más de un millón de indígenas.

Se puede observar en la oficialización de los idiomas por parte de la 'cultura nacional' que diversos pueblos indígenas de Latinoamérica pasan a reafirmarse y a reintegrarse en ese proceso de la interculturalidad, de la multiculturalidad, de la pluriculturalidad, del multilingüismo y de la diferencia. Son cincuenta y tres millones de seres que en este continente hablan lenguas indígenas.

Dentro de este apartado es obligante revisar lo que ha sido el principio de subalternidad en la que se ha mantenido la cultura de las etnias indígenas en este territorio desde la colonia española. Tomando en cuenta que una política de identidad en Latinoamérica tendería a depender de la transformación colectiva y de las condiciones sociales de producción del pueblo como sujeto colectivo, donde su identidad ha estado sustentada en la negación del principio subalterno al que han sido sometidas las etnias indígenas por más de cinco siglos, no se puede generalizar un concepto de pueblo indígena, porque ni siquiera puede tomarse de manera homogénea, sino como una figura heterogénea con contradicciones en su propia conformación múltiple e hibrida.

${ }^{4}$ Nombre de América en lengua karibe. 
En consecuencia, se puede señalar que a los pueblos indígenas se les siguió apuntalando la lógica de subalternidad, de exclusión, de discriminación y de falta de igualdad, al surgir formas de liberalismo muy avanzadas que las invisibilizaban o las negaban como una actualidad; con lo cual, en el soporte de las identidades latinoamericanas a lo largo de dos siglos, se creó un nuevo juego donde quedaban excluidas las políticas de apoyo a un grupo social tan desfavorecido, en función de potenciar las políticas de las diferencias sin contexto.

La superación del Estado nacional no puede ser sólo una reafirmación de las instituciones de la nación histórica, sino que debería ser una posibilidad de hacer evidente la realidad de una relación de desigualdad social, y buscar con ello que se cumpla un proceso de gestión, de inserción, de empoderamiento de una identidad.

El asunto de una visibilización en términos de «celebración de la diferencia y de la alteridad $»^{5}$ no es darle respuesta al sujeto previamente silenciado y anónimo, como venía siendo la cultura de los pueblos indígenas. Se requeriría, por tanto, un cambio a partir de un proceso de constante desplazamiento, de la deconstrucción del discurso del Estado nacional, para con ello permitir que una cultura de lo popular-étnico sea una articulación de colaboración o solidaridad con aquello que está más allá de la posibilidad de representación, con la realidad concreta.

En consecuencia, la propuesta retorna a la idea de una «heterogeneidad radical del subalterno» ${ }^{6}$ y no a las demandas de una restauración conservadora que conlleve formas de territorialidad cultural a la manera del apartheid de tolerancia estadounidense, fomentada por los sistemas internacionales, como puede ser el rescate de la cultura indígena a través de sus propias expresiones folklóricas.

Es el cambio hacia una definición de identidad cultural lo que tiene que ver con la universalización de un bloque de comunidades de voluntad singular y que son contradictorias en sí mismas. De allí que se requiera un nuevo tipo de política que interpele al pueblo indígena como ese bloque de comunidades de voluntad, internamente fragmentadas, dentro de una nación o dentro de una confederación de naciones existentes o posibles ${ }^{7}$, y donde la representación del pueblo indígena (de las etnias) como la víctima de la historia en América Latina deje de ser una imagen constante para transformarse en la expresión de su capacidad como sujeto de un proyecto de transformación por derecho propio, que puede establecer una solidaridad activa entre los que operan en una dinámica de anonimatos e improvisación y que están en constante transitividad hacia una transformación social estructural.

Para todo ello se requiere una política específica de deconstrucción de la identidad latinoamericana basada en la reconstitución del pueblo indígena como un bloque integrado a una nueva forma de hegemonía más igualitaria y más respetuosa de la comprensión de las prácticas sociales de estos pueblos y, al mismo tiempo, permitir localizar líneas divisorias entre las relaciones de dominación que continúan siendo producidas y que se extienden al mundo de la cultura identitaria. Sean estos venidos de los paradigmas de una izquierda que también ha generado crisis o de las nuevas perspectivas teóricas asociadas al postcolonialismo. Ambas han buscado en la legitimación de las periferias una presunción de igual valor para las culturas en relación, lo cual se traduce en una demanda de reconocimiento cultural de lo excluido.

\section{Bibliografía}

BÁEz, Fernando. El saqueo cultural de América Latina. México D.F: Random House Mondadori, 2008.

Beverley, John. Política de la teoría. Ensayos sobre subalternidad y hegemonía. Caracas: Fundación CELARG, 2011.

BIDEGAIN, Marcela. Resistencia y transformación social. Buenos Aires: Atuel, 2007.

\footnotetext{
${ }^{7}$ Construir la política de la multitud hoy en día, requeriría al mismo tiempo, nuevos conceptos de nación, de identidad e intereses nacionales (Cfr. Beverley).

${ }^{5}$ Cfr. Beverly.

${ }^{6}$ Idem. 
Fernández Retamar, Roberto. Para una teoría de la literatura latinoamericana y otras aproximacione. Cochabamba: Nuevo Tiempo, 1977.

Mariátegui, José Carlos. «¿Existe un pensamiento hispanoamericano?». Picón Salas: Historia de la cultura y cosmopolitismo. Ed. Oscar Rivera-Rodas. Caracas: Casa de Rómulo Gallegos, 2011.

Negri, Antonio y Danilo Zolo. «El Imperio y la Multitud. Un diálogo sobre el Nuevo Orden de la Globalización», Revista Facultad de Derecho y Ciencias Políticas de la Universidad de Medellín, 39(110), 2009: 15-31.

Organización de Estados Americanos. Documentos Básicos en materia de Derechos Humanos en el Sistema Interamericano. Washington: Comisión Interamericana de Derechos Humanos, 2007.

Organización de Naciones Unidas. Declaración Universal de los Derechos Humanos. Ginebra: Organización de Naciones Unidas, 1948.

PAz, Octavio. Puertas al campo. Barcelona: Seix Barral, 1972.

Picón Salas, Mariano. «Europa América, Preguntas a la esfinge de la cultura». Picón Salas: Historia de la cultura y cosmopolitismo. Ed. Oscar Rivera-Rodas. Caracas: Casa de Rómulo Gallegos, 2011.

— «Hispano América: Posición crítica». Picón Salas: Historia de la cultura y cosmopolitismo. Ed. Oscar RiveraRodas. Caracas: Casa de Rómulo Gallegos, 2011.
— «Regreso de tres mundos. Un hombre en su generación». Picón Salas: Historia de la cultura y cosmopolitismo. Ed. Oscar Rivera-Rodas. Caracas: Casa de Rómulo Gallegos, 2011

Roa Bastos, Augusto. «Imagen y perspectiva de la narrativa latinoamericana actual». Picón Salas: Historia de la cultura y cosmopolitismo. Ed. Oscar Rivera-Rodas. Caracas: Casa de Rómulo Gallegos, 2011.

UNESCO. Convención sobre la protección y la promoción de la Diversidad de las expresiones culturales, 2005. http:/ / unesdoc.unesco.org/images/0014/001429/1429 19s.pdf.

Uslar Pietri, Arturo. En busca del Nuevo Mundo. México D.F: Fondo de Cultura Económica, 1969.

Velasco Toro, José. «Espacio y territorio: ámbito de la etno-identidad». CESLA, 10, 2007, pp. 53-70.

Velásquez, Ronny. «Encuentro Internacional sobre Lenguas en peligro de extinción». México D.F.: Instituto Nacional de Antropología de México, 2012.

- Foro del futuro. Caracas: Instituto de Previsión y Asistencia Social del Ministerio de Educación, 2008.

- Los Akawaio, indígenas del esequibo, territorio en reclamación. Caracas: Consejo Nacional de Universidades y Oficina de Planificación del Sector Universitario, 2010.

ZEA, Leopoldo (1976). El pensamiento latinoamericano. Barcelona: Ariel. 